Лазарь Милентиевич

Университет в Нови-Саде

Философский факультет

Отделение славистики

milentijeviclazar@mail.ru
УДК 821.161.1.09"18"

https://doi.org/10.18485/slavistika.2020.24.2.25

оригинални научни рад

примљено 28.07.2020.

прихваћено за штампу 18.09.2020.

\title{
ДОСТОЕВСКИЙ КАК ВЕХА В ДУХОВНОМ СТАНОВЛЕНИИ С.И. ГЕССЕНА
}

В данной статье рассматривается духовный путь Сергей Иосифовича Гессена, важной частью которого стало обращение к творчеству Достоевского. Ключевые работы о Достоевском были написаны в эмиграции, что свидетельствует о значимости художественного и публицистического наследия Достоевского как для всей эмиграции, так и для формирования мировоззрения С.И. Гессена. Корпус философских работ Гессена, включающий опубликованные сочинения, архив, лекции, говорит об особой роли Достоевского в философской мысли С.И. Гессена, и анализ этих работ позволяет проследить как кристаллизируется и выделяется «тема Достоевского» в духовном становлении.

Ключевые слова: С.И. Гессен, Ф.М. Достоевский, русская эмиграция, Братья Карамазовы, Бесы.

This article discusses the spiritual path of Sergei Iosifovich Hessen, an important part of which was the appeal to the work of Dostoevsky. Key works about Dostoevsky were written in exile, which indicates the importance of Dostoevsky's artistic and journalistic heritage for the Russian emigration as well as shaping the worldview of Hessen. The corpus of Hessen's work, which includes published works, archives and lectures, speaks about the importance of Dostoevsky in the philosophical thought of S. I. Hessen, and the analysis of these works allows us to trace how the "theme of Dostoevsky" is crystallized as part of spiritual growing up.

Keywords: S.I. Hessen, F.M. Dostoevsky, good, evil, tragedy, emigration, The Brothers Karamazov, Demons.

Философское и педагогическое дарование С.И. Гессена не раз высоко оценивалось многими видными богословами и философами. В частности, В.В. Зеньковский, писал, что в философской и творческой мысли Гессена трансцендентализм оставил значительный след, тесным образом уживаясь с опытами метафизики и диалектическим методом. В.В. Зеньковский, со своей стороны, отмечает, что Гессен «яснее и острее других выразил позицию трансцендентализма в сфере антропологии» (Зеньковский 2001: 662). Н.О. Лосский, с другой стороны, включает С.И. Гессена в ряд представителей трансцендентально-логического идеализма и считает, что «при разработке проблемы этики и социальной философии С.И. Гессен <..> подходит вплотную к интуитивизму и стремится расширить его при помощи концепции практической волевой интуиции, которую называет „волезрением“» (Лосский 2011: 425)

Б. В. Яковенко в Гессене отмечал разностороннего исследователя, заступавшего оригинальную концепцию трансцендентно-диалектического онтологизма, который, как считает упомянутый автор, основывается на трех идеях: «1) многообразия и многослойности бытия; 2) неисчерпаемости Абсолюта никакой 
из уже воплощенных и выраженных сфер действительности; 3) и идее творческой, совершенствующейся природы диалектического процесса, в котором высший принцип остается в ,увиденном“ низшем, без полного снятия последнего, а только в более совершенном существовании их обоих» (Яковенко 2003: 417).

В. П. Прищепа подчеркивал, что в творчестве писателей первой волны эмиграции ${ }^{1}$, к которым относится Гессен, выделялись три задачи: «1. Сохранить память о дореволюционной России и ее национальном самосознании, цивилизации и духовных ценностях. 2. Стремление влиять на общественную жизнь в Советской России, добиваясь политических перемен. 3. Осмысление трагического для человеческого опыта социалистической революции в России» (Прищепа 1994).

На примере судьбы и творчества Гессена в очередной раз подтверждаются сказанные Ремизовым слова в 1919-ом году, когда страна проходила через страшный кризис: «Достоевский - это Россия. Без Достоевского - нет России» (Ремизов 2000: 358). Почти однозначно можно сказать, что «эмиграция первой волны неизменно ,держит в уме“ автора „Бесов“. Более того, он - своего рода сквозной сюжет, мера и точка отсчета в главном историческом споре: что случилось с Россией, каким представляется ее прошлое и есть ли у нее будущее?» (Волгин 2007). Надо отметить, что «особую роль сыграло его (Гессена - прим Л.М.) участие в работе организованного А. Бемом, литературоведом и активным деятелем русского зарубежья, Семинарии по изучению Достоевского при Русском народном университете в Праге» (Ратушина 2015: 114).

Если говорить об исследовательских дисциплинах, в рамках которых писал С. Гессен, то наряду с теоретической философией, социальной философией, философией образования выделяются работы, направленные на исследование метафизических и антропологических вопросов. Выискивание ответов на указанные вопросы привело Гессена к многоракурсной интерпретации Достоевского ${ }^{2}$, на основании творчества которого он построил многие философско-антропологические положения, что в то же время ознаменовало восстановление прерванной дореволюционной традиции. Таким образом, можно говорить об активном использовании кодов литературных произведений классика, и «через Достоевского Гессен по сути обращается к христианским истокам русской религиозной философии» (Ермишин 2012: 105).

К серии текстов Гессена, которые связаны с Достоевским и темами Достоевского, можно приписать несколько работ: «Трагедия добра в „Братьях Кара-

\footnotetext{
${ }^{1}$ Представляется весьма важным вопрос осмысления культурной миссии русской эмиграции в общецивилизационном процессе, в котором, несмотря на обособления от Советского государства, происходило стремление к диалогу с русской традицией и оставшейся в России интеллигенцией. (см. подроб. (Беляев 2005), (Кишкин 1995)).

${ }^{2}$ Н.В. Очироконова в кандидатской диссертации настаивает на том, что исследования проблемы человека привели С.И. Гессена к творчеству Достоевского, в соответствии с чем философом «была разработана оригинальная философско-антропологическая концепция, органически связанная с выработкой решения ряда проблем развития образования. Это обстоятельство определило характер основных философско-антропологических построений мыслителя и педагога, направленных на создание концепции свободной личности путем усвоения духовной культуры». (Очироконова 2005)
} 
мазовых Достоевского» (1928), «Борьба утопии и автономии добра в мировоззрении Ф.М. Достоевского и Вл. Соловьева» (1931), «Трагедия зла (философский смысл образа Ставрогина) (1932). Помимо прочего, к уже перечисленным работам можно вполне оправдано добавить и большинство текстов, в которых имя Достоевского или сквозит в содержании, или же нигде не упоминается, но чувствуется «вибрация» его мысли, которая свидетельствует о врастаний образов Достоевского в философский универсум Гессена.

На пути развития философско-антропологических идей Гессен в творчестве Достоевского увидел нечто «соприродное собственным размышлениям о мире и человеке $<\ldots>$ В этом отношении интерес С.И. Гессена, русского философа и педагога, к творческому наследию Ф.М. Достоевского закономерен и касается преимущественно „метафизического содержания“ произведений писателя» (Кошечко 2014: 57). Сам Гессен впоследствии, подводя итоги своей работы, писал, что исследование ключевых идей, образов и мотивов творчества Достоевского, - это одно из самых удавшихся мест в его работе. Очень важно упомянуть, что возвеличивание идей и постулатов Достоевского для Гессена отнюдь не сводилось к слепому подражанию великому мыслителю. Сергей Иосифович считал, что если единственная цель ученика - охранение наследства учителя, «во что бы то ни стало подтверждая выводы и предвидения учителя, он не только не создаст ничего нового и не двинет вперед дела своего учителя, но и не сохранит последнее» (Гессен 1924: 293). В подтверждение этого он приводит пример того, что именно благодаря Платону, - в своей диалектике ушедшему от Сократа, - а не Ксенофонту, - желавшему остаться верным преданию учителя, - философия Сократа сохранилась и стала неотъемлемым элементов всего последующего философствования. И это тем не менее позволило Платону создать собственную философскую систему. Сохранение и жизненность учения или предания поддерживается лишь «в диалектической сопряженности с противостоящим ему началом <..> частично отвергнутое, остается предание самим собой» (Гессен 1924: 294, прим. - курсив и пункт. С.И. Гессена).

Идея написания статьи о Достоевском была озвучена в 1925-ом году в одном письме к редактору Современных Записок, и данное намерение прямым образом связано с циклом лекций и докладов, зачитанных в Семинарии. Но задолго до написания первой статьи, которая, собственно, будет посвящена творчеству Достоевского, в 1924-ом году выходит работа под названием Крушение утопизма. Автор определяет, что за утопизмом следует и максималистичность, которая проявляются в насаждении порядка, должного упразднить всякое возможное зло. И здесь Гессен указывает на то, что «уже Достоевский в „Великом инквизиторе“" с необычайной прозорливостью показал эту связь утопизма с иезуитизмом. Он показал и другое: средства поглощают цель. Плененная средствами, цель непрерывно подменяется последними и в конце концов ускользает из поля зрения утописта» (Гессен 1924: 288). Действительность терпит по отношению к себе механическое отношение, и осуществление задач отодвигается в неопределенно отдаленное будущее. Таким образом, идея утопизма, считает Гессен, приводит к стиранию всех различий окружающей конкретной действительности. 
В данном случае может произойти страшная подмена и «наихудший вид зла, ибо зло здесь лишь наиболее лицемерно сокрылось под личиной добра. Отсюда огульное отрицание утопизмом всего того, что не есть полнота утверждаемого им самим идеала: вся история есть для него сплошное нагромождение заблуждений и ошибок, господство одного только зла» (Гессен 1924: 278). Зло мелькает в самом желании построить новый мир на голом основании разрушенного. Как уже видно из вышесказанного, отсюда вытекает вопрос происхождения в мире зла, которое в данной работе раскрывается как нечто всемогущее: «зло не разбирает свободных и несвободных, правых и виноватых и, не наталкиваясь на сопротивление, направляется одинаково на всех, кого оно встречает на своем пути» (Гессен 1924: 290).

В еще одной работе Сергей Иосифовича, которая появилась под названием Борьба утопии и автономии добра в мировоззрении Ф.М. Достоевского и Вл. Соловьева рассматриваются похожие вопросы. В этой статье автор явно отдает предпочтение Достоевскому за то, что он, мыслит автор, преодолел «историческую ограниченность своего мировоззрения» (Гессен 1931: 273-274), в то время как Соловьев «оказался слишком в плену у своих утопических надежд и чаяний» (Гессен 1931: 274). Гессен отмечает, что при огосударствлении церкви случится подмена Христовой любви «формальным, человеческим началом права» (Гессен 1931: 276). Только проникновение идеала Христова и оцерковление жизни могут дать подлинное, а не мнимое усовершенствование учреждений. В Братьях Карамазовых, делает заключение Гессен, Достоевский преодолел всякую тенденциозность и утопическую идею, которая бы приблизила его к свободной теократии. Зосима, отдавая должное суждениям Ивана и о. Паисия, весьма осторожно относится к утопическим надеждам («Правда, - усмехнулся старец, - теперь общество христианское пока еще само не готово и стоит лишь на семи праведниках < ..> (Достоевский 1976: 61)), хотя и говорит о Царстве Божием, которое им мыслится вознесенным над трагическими противоречиями земного существования. В продолжение указанной мысли, отмечает Гессен, даже «рассудочный оптимизм» Великого инквизитора, позволяющий злодеяния как необходимый момент во времени, «только еще резче оттеняет безрадостный, угрюмый, безблагодатный характер его сознания, присущий всякому утопизму вообще. Утопизм оптимистичен, но безрадостен, это есть „несчастное сознание“ по преимуществу» (Гессен 1931: 288).

В 1928-ом году выходит ключевая работа под названием Трагедия добра $в$ „Братьях Карамазовых“ Достоевского, которая ознаменовала новый период в осмыслении идей на тему творчества Достоевского. В данной работе С.И. Гессен следует традиции русских религиозных философов, отмечая особенную «образность», «символичность» и многослойность творчества Достоевского: «Если существо всякого искусства заключается в символической многозначности его образов, впервые сообщающей им измерение глубины и отличающей их от плоского отображение действительности, то в больших романах Достоевского, особенность эта доведена до своей почти предельной степени» (Гессен 1928: 308). Автор говорит, что архитектоника произведений Достоевского состоит из нескольких уровней: эмпирического, метафизического и мистического. Первый, то есть эмпирический, план состоит из собственно фабулы его произведений, 
в которой даются столкновения разных героев, и психологической платформы, говорящей о глубокой и трагической борьбе в человеческой душе. Во втором метафизическом плане, считает Гессен, показана сверхчувственная реальность идей, и здесь «судьба людей определяется в последнем счете именно их трагической антиномичностью и их логикой, часто не менее разрушительной» (Гессен 1928: 308). Третий слой Гессен относит к мистическому пласту бытия, в котором сопрягаются все упомянутые сферы друг с другом. В этом слое пласты «переплетены в единую ткань совокупного действия, так что потустороннее не только знаменуется эмпирическим, но всецело пронизывает его, просвечивается в нем» (Гессен 1928: 309). Достоевский приходил к выводу, что не разум и не чувства определяют моральные движения, а только постоянным мистическим ощущением Божественного присутствия: «Бог взял семена из миров иных и посадил их в землю, и взрастил сад свой; но все живет на земле касанием таинственным мирам иным». (Достоевский 1976: 290)

Трехступенчатую структуру автор использует и в рассматривании концепта «добра», определяя, что «образы трех братьев символизируют собой три аспекта или три ступени добра» (Гессен 1928: 309). Этот вопрос получает дальнейшую разработку применительно к силе зла, воплотившемся в образе Смердякова, который, по мнению Гессена, является «слугой всех трех искаженных личин добра» (Гессен 1928: 309).

Дмитрий Карамазов воплощает «естественную ступень Добра, как оно раскрывается на пороге природы, до всякой рефлексии и почти что до самосознания, в непосредственном, как бы инстинктивном чувстве „природного человека“» (Гессен 1928: 311). В нем представлено страстное переживание этического разлада мира, созерцание как самого низшего, так и самого высшего, что в дальнейшем находит выражение в трех чувствах, - в чувстве стыда, жалости и благоволения, - переводящих его животную жизнь в сферу «нравственно-ценного»..

Затем Гессен выделяет «добро», проникнутое нотой рефлексии и воплощенное в образе Ивана Карамазова. Карамазовский безудерж в нем выражен в страстном требовании рационального смысла. «Жизнь должна быть оправдана, - пишет Гессен, - а так как непосредственная, наивная вера - такая, какою верит еще его брат Дмитрий - им уже утрачена, он вызывает жизнь на суд разума» (Гессен 1928: 313). Весьма открыто ставится вопрос интеллектуалистической теодицеи, в которой добро отождествляется с завершенной в рамках времени полнотой бытия. Писатель указывает на существование двух планов бытия: он сравнивает реальный и невещественный мир с двумя линиями, которые могут сойтись лишь в сферах, не имеющих пределов и границ. Достоевский не раз размышлял над темой неостановимости процесса человеческого развития, который является подтверждением обращенности человека к бесконечности, представляющей надстройку земного бытия: «Ибо если б не было бесконечности, не было бы и конечности, немыслима бы она была. А если есть бесконечность, то есть Бог и мир другой, на иных законах, чем реальный (созданный) мир». (Достоевский 1984: 43)

В образе Ивана, утверждает Гессен, Достоевский приступает к рассматриванию вопроса, который будет детальнее разработан на примере Алеши Карамазова, - добра как любви. Случай Катерины Ивановны и Дмитрия говорит о 
том, что «любовь нельзя требовать „из долга“, ибо она вообще есть не требование разума, а дар благодатный, почему она и принадлежит не столько к долженствованию, сколько к бытию, разумеется к бытию высшего порядка <..>> (Гессен 1928: 320). Из этого следует, что добро не является самодовлеющим и самонаправленным, но пребывает в превышающем его начале, то есть в Боге. Такой путь раскрывает трагедию долга без любви и свободы без Бога, устанавливает постоянное колебание, которое грозит возможностью вырождения, искажающим добро. Об этом говорят судьбы Раскольникова, Смердякова и Великого инквизитора.

Пример Алеши демонстрирует, что высшая ступень добра никак не отрицает ни долг, ни естественные начала нравственности. Но в то же время долг освобождается от ригористической узости, что и показано в готовности Алеши участвовать во лжи и помочь Дмитрию совершить побег. Это, утверждает Гессен, отнюдь не отрицает настоятельность, требовательность и даже повелительность внутреннего долга, о котором говорит Зосима: «Делай неустанно. Если вспомнишь в нощи, отходя ко сну: «я не исполнил, что надо было», то немедленно возстань и исполни». (Достоевский 1976: 291) «Долг, - пишет Гессен, продолжает по-прежнему повелевать, но он уже не исключает любви» (Гессен 1928: 325).

В противовес безлюбовному состоянию мира, о котором говорит Иван, определяет Гессен, автор рисует образ Алешы Карамазова: «“Все этого юношу любили, где бы он ни появлялся“, да и сам Алеша в свою очередь обладал прекрасным даром той бескорыстной любви к ближнему, которая не знает никакого внутреннего разлада, будучи опять самой жизнью во всей ее неразъедаемой рефлексией непосредственности» (Гессен 1928: 322). В такой, как отмечает Сергей Иосифович, «дарящей добродетели Алеши» присутствует даже эстетический момент, основные тона которого веселие и радость перед Божьим творением: «Любите все создание Божие, и целое, и каждую песчинку, - говорит старец Зосима. - Каждый листик, каждый луч Божий любите. Любите животных, любите растения, любите всякую вещь. Будешь любить всякую вещь, и тайну Божию постигнешь в вещах. Постигнешь однажды и уже неустанно начнешь ее познавать все далее и более, на всяк день. И полюбишь, наконец, весь мир уже всецелою, всемирною любовью» (Достоевский 1976: 289). Если Иван заговаривает невозможность любви к ближним, заместо которой вводится любовь к дальнему, Алеша как раз своим примером показывает, что любовь не всегда действует в соответствии с общими правилами, а «возможно теснее прилепляется к индивидуальному и неповторимому стечению обстоятельств. Для нее цель всякой жизни лежит в ней самой: будь то личность в целом или только сейчашний отрез личного бытия <...>» (Гессен 1928: 324). Таким образом, ближнее и сегодняшнее в концепции Алеши Карамазова предпочитается дальнему. Любовь к ближнему конкретна, ее полнота осуществляется в определенный момент во времени, который преодолевается и переходит в вечность. Об этом говорит притча о луковке. Разрыв между прошлым и будущим сокращается, только если человек в должной мере смог просветить любовью отмеренный ему промежуток времени.

Вернемся к уже затронутому вопросу в статье Крушение утопизма, который касается присутствия в мире зла. Гессен приходит к заключению, что каждая 
ступень добра имеет с другой стороны соответствующую ступень зла: «Если на ступени природного добра зло является тоже в виде естественных страстей любострастия и гнева, если опасностью, подстерегающей „автономное добро“, является уединение или грех гордыни, под воздействием которого добро перекидывается в свою противоположность, то на высшей ступени добра зло вкрадывается в душу через уныние и отчаяние, которыми устанавливается в сердце вместо живой любви мертвое безразличие» (Гессен 1928: 327). Если деятельная любовь - это верхняя ступень добра, то уныние - это последняя ступень греха. Уныние, считает Гессен, воплощает зло и приводит к омертвению духа, смерти и небытию, что во многом соответствует древнему преданию православной церкви. Сила зла в том, что оно, как противоположность добра, действует посредством используемого им в своих целях добра.

Теме зла отдельно посвящена статья, вышедшая в 1932-ом году под названием Трагедия зла (философский смысл образа Ставрогина). В подтверждение того, что данная тема была крайне важной для Достоевского говорит то, что «из „памфлета“ выросло само собою творение с глубоким метафизическим содержанием, имеющее сверхвременное значение. Как это всегда бывало с Достоевским, он не в силах был совладать с множеством „обступивших его“ в то время идей и образов» (Гессен 1932: 44). В данной работе, как уже был случай в статье «Трагедия добра...», учитывается двупланность изображаемого мира Достоевского, в котором происходит соединение эмпирического и метафизического, профанного и сакрального. И только учитывая заостренность данных планов бытия, становится понятным стиль и напряженное действие романа.

Парадокс образа Ставрогина заключается в том, что его разум созерцает безверие собственного сердца, и он же толкает его к тому, чтобы желать веры, которая, однако, отсутствует из-за недостатка любви: «Неверующий, он стремится к вере, хочет ее, он непрерывно колеблется между безверием и желанием веры, и так как к необходимости веры приводит его все тот же разум, то его желание веры носит рассудочный и «надрывный» характер» (Гессен 1932: 52). Все его отношения с любимыми женщинам пропитаны обманом, ложью и смертным страхом. Грех, связанный со злом, в данной работе осмысляется в разных формах: 1) чувственно-витальной (любострастие и гнев), 2) душевнорациональной (гордость) и 3 ) духовно-волюнтарной (уныние).

Гессен считает, что трагедия Ставрогина - это «сознание потерянности уединившегося в себе самом разума» (Гессен 1932: 52), который делает его пленником и жертвой. Образ Ставрогина втянут во все формы греха, которые коронуются самой страшной третьей формой: унынием, безверием воли и внутренним отчаянием. В письме к Дарье Павловне ясно подчеркнуты нюансы духовного уединения, возрастающей формы гнева и гордости активного самоотъединения.

Невозможность выбраться из омута метафизического равнодушия и уныния проистекает из совершенного отсутствия в Ставрогине любви, почему перекрываются все пути к Богу, как всепрощающей любви. Несомненно, что он мучится, определяет Гессен, «сознанием неисполненной любви», однако для проникновенного чувства ему не хватает действенной веры в Бога. И изображение зла в образе Ставрогина получилось необычным, трагическим и в то же время в метафизическом смысле статичным: «зло отражается здесь в образах других ге- 
роев романа, которые кружатся вокруг него, как главного героя трагедии, и эта статичность метафизического действия еще усиливается от своего контраста с напряженной динамикой эмпирического действия романа». (Гессен 1932: 64).

Подводя итог, можно сказать, что модели и концепты художественных произведений Достоевского понудили Сергея Иосифовича Гессена рассмотреть этапы развития нравственной личности. В ходе своих размышлений он, во многом опираясь на творчество Достоевского, изучает концепты «добра», «зла», «трагедии», с целью определения вневременных ориентиров и обоснования шкалы нравственных и моральных ценностей.

\section{Использованная литература}

Беляев Сергей, А. Русская эмиграция в Европе в 20-е и 30-е годы. Вып.2. СанктПетербург: Алетейя, 2005.

[Beliāev Sergě̌, A. Russkaiā èmigrațiiiā v Evrope v 20-e i 30-e gody. Vyp.2. SanktPeterburg: Aleteĭiâ, 2005]

Волгин Игорь, Л. Достоевский в изгнании. Переписка И.С. Шмелева и И.А. Ильина, $2005<$ https://magazines.gorky.media/october/2007/8/dostoevskij-v-izgnanii. html $>02.10 .2020$.

[Volgin Igor', L. Dostoevskiǐ v izgnanii. Perepiska I.S. SHmeleva i I.A. Il'ina, 2005 $<$ https://magazines.gorky.media/october/2007/8/dostoevskij-v-izgnanii.html > 02.10.2020.]

Ермишин Олег, Т. «В поисках сверхличностных ценностей: философский путь С.И. Гессена». Философские науки 8, 2012: 97-109.

[Ermishin Oleg, T. «V poiskakh sverkhlichnostnykh tsennosteř: filosofskiı̌ put' S.I. Gessena». Filosofskie nauki 8, 2012: 97-109]

Кишкин Лев, С. «Русская эмиграция в Праге: печать, образование гуманитарные науки (1920 -1930-е годы)». Славяноведение 4, 1996: 3-10.

[Kishkin Lev, S. «Russkaiā èmigratsiiā v Prage: pechat', obrazovanie gumanitarnye nauki (1920-1930-e gody)». Slaviânovedenie 4, 1996: 3-10]

Зеньковский, Василий В. История русской философии. Москва: Академический Проект; Раритет, 2001.

[Zen'kovskiı̌, Vasiliǐ V. Istoriiâa russkoĭ filosofii. Moskva: Akademicheskiı̌ Proekt; Raritet, 2001]

Кошечко, Анастасия Н. «С.И. Гессен об экзистенциальной антропологии Ф.М. Достоевского». Философского-педагогическая концепция С.И. Гессена и современные проблемы образования, воспитания, культуры: сборник научных трудов Всероссийской научно-практической конференции с международным участием. Томск: Томский государственный университет, филологический факультет, 2014, 57-59.

[Koshechko, Anastasiiā N. «S.I. Gessen ob èkzistentsial'noĭ antropologii F.M. Dostoevskogo». Filosofskogo-pedagogicheskaiā kontseptsiia S.I. Gessena i sovremennye problemy obrazovaniia, vospitaniiā, kul'tury: sbornik nauchnykh trudov Vserossiǐskoĭ nauchnoprakticheskoŭ konferentșii s mezhdunarodnym uchastiem. Tomsk: Tomskiı̆ gosudarstvennyĭ universitet, filologicheskii fakul'tet, 2014, 57-59]

Лосский, Николай О. История русской философии. Москва: Академический Проект; Трикста, 2011. 
[Losskī̌, Nikolaĭ O. Istoriiā russkoĭ filosofii. Moskva: Akademicheskiĭ Proekt; Triksta, 2011]

Очироконова, Наталья В. Проблема человека в философии С.И. Гессена, 2005. $<\mathrm{http}$ ://cheloveknauka.com/problema-cheloveka-v-filosofii-s-i-gessena $>02.10 .2020$.

[Ochirokonova, Natal'iâ V. Problema cheloveka v filosofii S.I. Gessena, $2005<$ http:// cheloveknauka.com/problema-cheloveka-v-filosofii-s-i-gessena $>02.10 .2020$ ]

Прищепа, Валерий П. Литература русского зарубежья. Учебное пособие. Абаканский педагогический институт, 1994. <http://www.russofile.ru/articles/article 90.php> 02.10.2020.

[Prishchepa, Valeriı̌ P. Literatura russkogo zarubezh'iā. Uchebnoe posobie. Abakanskiı̌ pedagogicheskiı̌ institut, $1994<$ http://www.russofile.ru/articles/article_90.php $>02.10$. 2020]

Ратушина, Дарья В. «Сергей Гессен о Ф.М. Достоевском: эволюция философского пути». Гуманитарные исследования в Восточной Сибири и на Дальнем Востоке 4, 2015: 114-118.

[Ratushina, Dar'iā V. «Serger Gessen o F.M. Dostoevskom: èvoliưtsiīa filosofskogo puti». Gumanitarnye issledovaniiâ v Vostochnoĭ Sibiri i na Dal'nem Vostoke 4, 2015: 114-118]

Яковенко, Борис В. История русской философии. Москва: Изд-во Республика, 2003.

[IÄkovenko, Boris V. Istoriiā russkoĭ filosofii. Moskva: Izd-vo Respublika, 2003]

\section{Источники}

Гессен, Сергей И. «Крушение утопизма». Современные записки 19, 1924: 277-295.

[Gessen, Sergeǐ I. «Krushenie utopizma». Sovremennye zapiski, 1924: 277-295]

Гессен, Сергей И. «Трагедия добра в „Братьях Карамазовых“ Достоевского». Современные записки 35, 1928: 308-338.

[Gessen, Sergě̌ I. «Tragediiā dobra v „Brat'iakh Karamazovykh“ Dostoevskogo». Sovremennye zapiski 35, 1928: 308-338]

Гессен, Сергей И. «Борьба утопии и автономии добра в мировоззрении Ф.М. Достоевского и Вл. Соловьева». Современные записки 45, 1931: 271-305.

[Gessen, Sergeî I. «Bor'ba utopii i avtonomii dobra v mirovozzrenii F.M. Dostoevskogo i V1. Solov'eva». Sovremennye zapiski 45, 1931: 271-305]

Гессен, Сергей И. «Трагедия зла (Философский смысл образа Ставрогина)». Путь 36, 1932 (декабрь): 44-74.

[Gessen, Sergeĭ I. «Tragediiā zla (Filosofskiı̌ smysl obraza Stavrogina)». Put' 36, 1932 (dekabr'): 44-74]

Достоевский, Федор М. Собр. соч. в 30 тт. Т. 14. Ленинград: Наука, 1976.

[Dostoevski1̌, Fedor M. Sobr. soch. v 30 tt. T. 14. Leningrad: Nauka, 1976

Достоевский, Федор М. Собр. соч. в 30 тт. Т. 27. Ленинград: Наука, 1984.

[Dostoevskiı̌, Fedor M. Sobr. soch. v 30 tt. T. 27. Leningrad: Nauka, 1984]

Ремизов, Алексей М. Собр. соч. в 10 тт. Т.5. Москва: Русская книга», 2000.

[Remizov, Alekseǐ M. Sobr. soch. v 10 tt. T.5. Moskva: Russkaiā kniga», 2000] 


\section{Лазар Милентијевић}

\section{ДОСТОЈЕВСКИ КАО ПРЕКРЕТНИЦА У ДУХОВНОМ СТАНОВљЕЮУ С.И. ГЕСЕНА}

\section{Резиме}

У чланку се разматра утицај стваралаштва Достојевског на представника прве струје руске емиграције Сергеја Гесена. Симптоматично је да су прве фундаменталније и исцрпније студије Гесена о стваралаштву Достојевског биле написане у периоду када се он нашао у Прагу где је држао предавања и активно учествовао у кружоку А. Бема «Общество Достоевского» (Друштво Достојевског). Међутим, чак и они радови у којима основни циљ није преиспитивање и анализа појединих сегмената стваралаштва Достојевског, садрже велики број цитата и објашњења из романа Достојевског. То сведочи да је стваралаштво Достојевског било од есенцијалног значаја за формирање властитих судова Гесена.

Радови у којима су стваралаштво Достојевског и питања која из њега проистичу предмет истраживања настају у периоду од 1924. до 1932. године и углавном су објављивани у књижевном часопису «Современные записки» (Савремени записи). У тим радовима аутор издваја идеје „добра“, „зла“, „утопије“ и веома често примењује трочлану структуру у осмишљавању поменутих појмова који за њега представљају унивезалије у чијем дефинисању он тражи оријентире духовних и моралних вредности.

Кључне речи: С.И. Гесен, Ф.М. Достојевски, руска емиграција, „Савремени записи“. 